\title{
ARTICLE Effect of Egg Albumen, Vegetable Oil, Corn Bran, and Cooking Methods on Quality Characteristics of Chicken Nuggets Using Response Surface Methodology
}

OPEN ACCESS

$\begin{array}{ll}\text { Received } & \text { January 15, } 2018 \\ \text { Revised } & \text { July 22, } 2018 \\ \text { Accepted } & \text { July 30, } 2018\end{array}$

*Corresponding author: Ashok Kumar Pathera School of Bioengineeirng and Food

Technology, Shoolini University, Solan-173

229, Himachal Pradesh, India

Tel: +919991121920

E-mail: apathera@gmail.com

\author{
Ashok Kumar Pathera ${ }^{1,2,}{ }^{*}$, Charanjit Singh Riar ${ }^{1}$, Sanjay Yadav ${ }^{3}$, \\ and Pradeep Kumar Singh ${ }^{4}$ \\ ${ }^{1}$ Department of Food Engineering \& Technology, Sant Longowal Institute of \\ Engineering \& Technology, Longowal- 148 106, Punjab, India \\ ${ }^{2}$ School of Bioengineering and Food Technology, Shoolini University, Solan-173 229, \\ Himachal Pradesh, India \\ ${ }^{3}$ Department of Livestock Products Technology, Lala Lajpat Rai University of \\ Veterinary and Animal Sciences, Hisar-125 004, Haryana, India \\ ${ }^{4}$ Department of Livestock Products Technology, College of Veterinary Science and \\ Animal Husbandry, Rewa-486 001, Madhya Pradesh, India
}

\begin{abstract}
Response surface methodology was used to study the effect of egg albumen (5-15 g), vegetable oil (5-15 g), and corn bran (5-15 g) on sensory and textural (firmness and toughness) quality of chicken nuggets cooked by the oven, steam, and microwave methods. The egg albumen and vegetable oil had a positive linear effect but corn bran had a negative linear effect at $\mathrm{p}<0.01$ on sensory overall acceptability scores of nuggets. Firmness and toughness scores were increased significantly $(p<0.01)$ with the increase in corn bran level in the formulation. The optimum level of egg albumen, vegetable oil, and corn bran were obtained and validated. Cooking methods also affected the sensory and textural quality of nuggets. Steam cooked nuggets had higher values of sensory scores than oven and microwave cooked nuggets. Oven cooked nuggets showed higher values of firmness and toughness than steam and microwave cooked nuggets. Results of this study suggest that emulsion based meat products can be enriched with dietary fiber source like corn bran without compromising the sensory and textural quality of the products.
\end{abstract}

Keywords chicken nuggets, cooking methods, response surface methodology, sensory quality

\section{Introduction}

Non-meat ingredients plays important role in deciding the quality of emulsion based meat products. Generally processed meat products have good nutritional quality but lacks in dietary fiber content. The diets deficient in dietary fiber are associated with several health problems (WHO/FAO, 2003). The consumption of fiber-rich diets has

(C) Korean Society for Food Science of Animal Resources. This is an open access article distributed under the terms of the Creative Commons Attribution Non-Commercial License (http://creativecommons.org/licences/by-nc/3.0) which permits unrestricted non-commercial use, distribution, and reproduction in any medium, provided the original work is properly cited. 
been related to decreased incidence of several diseases and has a positive effect on health (Dhingra et al., 2012; Kaushik et al., 2015; Kumar et al., 2013). The use of cereals bran has been increased in a variety of emulsion based meat products in recent years. Previously, wheat and oat bran were added in chicken meat patties (Talukder and Sharma, 2010), rice bran in the emulsified pork meatballs (Huang et al., 2005), wheat bran in chicken nuggets (Pathera et al., 2017), corn bran in chicken sausages (Yadav et al., 2016), and wheat bran in beef patties (Sariçoban et al., 2009). Cereals bran acts as a functional ingredient in meat products and it also helpful in reducing the cost of meat products. But, instead of these beneficial functions, the use of bran reduces the overall sensory quality of meat products. It is necessary to maintain the sensory quality of meat products and use of other ingredients like egg albumen and vegetable oil are needed to overcome the negative effect of bran on sensory quality. Kalaikannan et al. (2007) improved the sensory scores of chicken patties by the addition of egg albumen, which contributed to enhancing the flavor, texture, and juiciness of the product. Verma et al. (2009) reported an increase in sensory scores as the level of sunflower oil incorporation increased in chicken nuggets.

The optimum level of ingredients can be obtained using the statistical tool response surface methodology. Previously, some researchers had studied the effects of ingredients on products quality and optimized the formulation for emulsion based meat products (Murphy et al., 2004; Pathera et al., 2017; Sariçoban et al., 2009). The type of cooking techniques affects the quality of meat products. The effect of dry or moist cooking on products quality was observed by Cholan et al. (2011) in chicken patties cooked by oven, steam, microwave, and frying techniques. Talukder and Sharma (2010) also studied the quality characteristics of steam and oven cooked patties incorporated with fiber. In this view, the present study was designed to optimize the level of egg albumen, vegetable oil, and corn bran in chicken nuggets prepared by oven, steam, and microwave cooking methods.

\section{Materials and Methods}

\section{Egg albumen}

Eggs were procured from local market and kept under refrigerated $\left(4 \pm 1^{\circ} \mathrm{C}\right)$ storage. Eggs were broken and albumen was separated from yolk manually for incorporation in the formulation.

\section{Vegetable oil}

Ginni brand refined groundnut oil of Amrit Banaspati Co. Limited, Rajpura, India was procured from the local market of Hisar, India.

\section{Corn bran}

Corn bran was obtained from Vitarich Agro Food (India) Limited, Kolkata, India. Microwave stabilization of corn bran was done as per method developed by Ramezanzadeh et al. (2000). The bran was grinded in an electrical grinder, passed through $1 \mathrm{~mm}$ sieve, packed in an airtight container and stored in a freezer $\left(-18^{\circ} \mathrm{C}\right)$ for further use.

\section{Broiler chicken}

Broiler birds of 1.5-2.0 kg weight and 6-7 weeks age reared under similar feeding and managemental conditions were slaughtered and dressed as per the standard procedure in the slaughter house of Department of Livestock Products Technology, Lala Lajpat Rai University of Veterinary and Animal Sciences, Hisar, India. Carcasses were washed thoroughly; 
breast and leg cuts were separated. Both the cuts were deboned manually after trimming of visible fat and connective tissue. Deboned meat from both the cuts was mixed in equal proportion and stored in a freezer $\left(-18^{\circ} \mathrm{C}\right)$ for further use.

\section{Experimental design}

Response surface methodology was used to study the effect of ingredients variable namely egg albumen, vegetable oil, and corn bran. The experiments were designed using the software, Design Expert trial version 9 (State-Ease, Minneapolis, MN). The experiments were based on Box-Behnken experimental design (Box and Behnken, 1960). Values of independent variables at three levels of the Box-Behnken design are presented in Table 1. The experimental design involved 17 experiments as presented in Table 2 in coded levels. Experiments were conducted for three different cooking methods viz. oven, steam, and microwave separately by using same experimental design. For each response assessed, the variables were divided into linear, interaction and quadratic effect. The responses (sensory overall acceptability, firmness, and toughness) for different experimental combinations were assessed by a second-degree polynomial equation.

$$
Y=\beta_{0}+\beta_{1} x_{1}+\beta_{2} x_{2}+\beta_{3} x_{3}+\beta_{12} x_{1} \cdot x_{2}+\beta_{13} x_{1} \cdot x_{3}+\beta_{23} x_{2} \cdot x_{3}+\beta_{11} x_{1}{ }^{2}+\beta_{22} x_{2}{ }^{2}+\beta_{33} x_{3}^{2}
$$

Where $Y$ is the estimated response, the coefficients of the polynomial were represented by $\beta 0$ (constant), $\beta 1, \beta 2, \beta 3$ (linear effects); $\beta 12, \beta 13, \beta 23$ (interaction effects); $\beta 11, \beta 22, \beta 33$ (quadratic effects). The adequacy of the generated model was determined by evaluating the lack of fit, coefficient of correlation $\left(\mathrm{r}^{2}\right)$, and the Fisher test value (F-value) obtained from the analysis of variance (ANOVA). The regression coefficients were used to generate the graphical presentation of response surface three-dimensional plots by using the Design Expert trial version 9 (State-Ease, Minneapolis, MN).

\section{Preparation of nuggets}

The frozen meat was thawed and cut into chunks for mincing. An electrical mincer (MADO Primus, model MEW 613, Germany) was used for mincing with $4 \mathrm{~mm}$ plate. Minced meat (100 g), common salt (2.5 g), sodium tripolyphosphate (400 $\mathrm{mg}$ ), sodium nitrite (20 mg), spice mix ( $3 \mathrm{~g})$, condiments paste ( $4 \mathrm{~g})$, refined wheat flour $(3 \mathrm{~g})$, and chilled water $(12 \mathrm{~g})$ were used in constant amount with the variable amount of egg albumen (5-15 g), vegetable oil (5-15 g), and corn bran (5-15 g). Mixing of constant and variable ingredients was carried out in a bowl chopper (Stadler Corporation, India) to prepare the emulsion. The batches of emulsion were prepared as per experimental design (Table 2) and divided into 3 parts, each for oven, steam, and microwave cooking. Equal weight of emulsion was stuffed in rectangular moulds of same size and was cooked by oven (in a preheated electrical oven of Ditz Electricals Ltd, India, at $165^{\circ} \mathrm{C}$ temperature for 35 minutes), steam (in a closed container at sim flame for $30 \mathrm{~min}$ ), and microwave oven (Samsung, model C103FL, at 2,450 $\mathrm{MHz}$ and $900 \mathrm{~W}$ ) for $5 \mathrm{~min}$

Table 1. Levels of independent variables obtained from the Box-Behnken design

\begin{tabular}{lcccc}
\hline & & & Levels in coded form \\
Independent variables $(\mathrm{g})$ & Code & -1 & 0 & +1 \\
\cline { 2 - 4 } Egg albumen & $x_{1}$ & 5 & 10 & 15 \\
Vegetable oil & $x_{2}$ & 5 & 10 & 15 \\
Corn bran & $x_{3}$ & 5 & 10 & 15 \\
\hline
\end{tabular}


Table 2. Box-Behnken experimental design employed for development of chicken nuggets

\begin{tabular}{|c|c|c|c|c|c|c|c|c|c|c|c|c|}
\hline \multirow{3}{*}{$\begin{array}{l}\text { Experiment } \\
\text { No. }\end{array}$} & \multirow{2}{*}{\multicolumn{3}{|c|}{$\begin{array}{c}\text { Coded } \\
\text { variables }\end{array}$}} & \multicolumn{9}{|c|}{ Experimental response } \\
\hline & & & & \multicolumn{3}{|c|}{ Oven cooked nuggets } & \multicolumn{3}{|c|}{ Steam cooked nuggets } & \multicolumn{3}{|c|}{ Microwave cooked nuggets } \\
\hline & $x_{1}$ & $x_{2}$ & $x_{3}$ & OAA & Firmness & Toughness & OAA & Firmness & Toughness & OAA & Firmness & Toughness \\
\hline 1 & 0 & 0 & 0 & 6.67 & 13.05 & 76.12 & 7.33 & 11.12 & 75.95 & 6.50 & 9.55 & 63.12 \\
\hline 2 & 0 & 0 & 0 & 6.67 & 11.88 & 72.57 & 7.33 & 10.15 & 66.56 & 6.50 & 9.24 & 65.77 \\
\hline 3 & 1 & 1 & 0 & 7.17 & 11.10 & 69.47 & 7.50 & 9.01 & 59.36 & 6.83 & 8.42 & 58.55 \\
\hline 4 & 1 & 0 & -1 & 7.50 & 9.44 & 67.39 & 7.58 & 7.72 & 53.82 & 7.33 & 7.85 & 54.86 \\
\hline 5 & -1 & 0 & -1 & 7.00 & 9.36 & 72.56 & 7.33 & 8.18 & 57.41 & 7.00 & 8.50 & 70.40 \\
\hline 6 & -1 & -1 & 0 & 6.17 & 12.63 & 87.55 & 6.42 & 12.11 & 86.43 & 6.00 & 9.76 & 72.25 \\
\hline 7 & 0 & -1 & 1 & 5.67 & 13.65 & 97.65 & 6.17 & 12.53 & 86.67 & 5.84 & 12.22 & 84.18 \\
\hline 8 & 1 & 0 & 1 & 6.33 & 12.89 & 78.84 & 6.67 & 11.57 & 76.82 & 6.00 & 11.16 & 83.71 \\
\hline 9 & -1 & 1 & 0 & 6.33 & 11.64 & 71.31 & 7.17 & 9.36 & 72.63 & 6.50 & 9.11 & 79.56 \\
\hline 10 & 0 & 1 & -1 & 7.33 & 9.97 & 76.44 & 7.58 & 7.85 & 54.98 & 7.17 & 8.99 & 68.58 \\
\hline 11 & 1 & -1 & 0 & 6.50 & 12.12 & 83.51 & 7.00 & 9.15 & 70.63 & 6.67 & 8.74 & 68.91 \\
\hline 12 & 0 & 0 & 0 & 6.67 & 12.93 & 78.37 & 7.33 & 11.35 & 75.44 & 6.50 & 9.50 & 63.42 \\
\hline 13 & 0 & 0 & 0 & 6.67 & 12.55 & 74.56 & 7.17 & 10.75 & 69.18 & 6.50 & 9.38 & 66.47 \\
\hline 14 & 0 & 0 & 0 & 6.50 & 12.25 & 75.99 & 7.17 & 10.75 & 63.66 & 6.83 & 9.40 & 62.45 \\
\hline 15 & 0 & -1 & -1 & 7.33 & 9.56 & 71.68 & 7.50 & 8.66 & 56.38 & 7.00 & 8.88 & 65.58 \\
\hline 16 & 0 & 1 & 1 & 6.33 & 13.50 & 82.97 & 6.67 & 11.86 & 82.71 & 6.00 & 11.35 & 78.44 \\
\hline 17 & -1 & 0 & 1 & 6.00 & 12.61 & 84.30 & 6.17 & 12.45 & 85.55 & 5.67 & 11.98 & 86.14 \\
\hline
\end{tabular}

OAA, overall acceptability; $n=18$ for OAA and $n=6$ for firmness and toughness, mean values are presented for each experiment.

(Pathera et al., 2016). Cooked emulsions were cooled to room temperature. Nuggets were prepared by slicing cooked emulsion to $3 \times 3 \times 3 \mathrm{~cm}^{3}$ size and analyzed for overall sensory acceptability and textural (firmness and toughness) parameters.

\section{Sensory analysis}

Nuggets samples were warmed before serving and coded samples were presented before panelists (a semi-trained panel of research scholars and faculty members of the Department of Livestock Products Technology, Lala Lajpat Rai University of Veterinary and Animal Sciences, Hisar, India). Panelists were experienced in sensory analysis of meat products. Sensory overall acceptability scores (in terms of color and appearance, flavor, texture, tenderness, and juiciness) were evaluated using 8 -point descriptive scale, where 8 indicate extremely acceptable and 1 indicates extremely unacceptable.

\section{Texture analysis}

Nuggets samples were subjected to texture analysis at room temperature. Results were measured in terms of Firmness (N) and toughness (N.sec) using TAHD Plus Texture Analyser (Stable Micro Systems, England). Cubic samples of $15 \times 15 \times 15 \mathrm{~mm}$ size were cut by Warner Bratzler cutting blade having rectangular notch. Force time cutting curves were obtained with a 50 $\mathrm{kg}$ load cell applied at a cross-head speed of $2 \mathrm{~mm} / \mathrm{s}$. The maximum force required to cut the sample was taken as an index of firmness and the total positive area under the curve was taken as toughness. 


\section{Statistical analysis and optimization}

The statistical analysis was performed by same software, Design Expert trial version 9 (State-Ease, Minneapolis, MN). The significance of parameters for each response was assessed using the $\mathrm{F}$ test. Numerical multi-response optimization technique was applied to determine the optimum level of egg albumen, vegetable oil, and corn bran for three different formulations. The independent variables (egg albumen, vegetable oil, and corn bran) and dependent variables (OAA, firmness and toughness) were kept within experimental range with maximum desirability (Prasad and Singh, 2014). The desirability was calculated by following equation and the highest desirability was selected.

$\mathrm{D}=\left(\mathrm{d}_{1} \times \mathrm{d}_{2} \times \ldots \mathrm{d}_{\mathrm{n}}\right)^{1 / \mathrm{n}}$

$\mathrm{D}=$ overall desirability, $\mathrm{d}=$ desirability, $\mathrm{n}=$ response

\section{Results and Discussion}

\section{Sensory overall acceptability}

Table 1 shows the effects of added albumen, oil, and corn bran levels on the sensory overall acceptability of the oven, steam, and microwave cooked chicken nuggets. In addition, Fig. 1 illustrates these effects as three-dimensional graphs where the direction of the effects of variables on sensory overall acceptability can be seen. The sensory overall acceptability scores of the oven, steam, and microwave cooked nuggets varied from 5.67 to 7.5, 6.17 to 7.58, and 5.67 to 7.33 respectively. The models are significant $(p<0.01)$ for oven, steam, and microwave cooked nuggets (Table 3 ). For all the nuggets, sensory scores increased significantly $(\mathrm{p}<0.01)$ with the increase in the level of albumen or oil (Fig. 1). The incorporation of albumen and oil increased the sensory quality. Pathera et al. (2017) reported an increase in sensory scores of chicken nuggets with the increase in albumen and oil level in the formulation. Kalaikannan et al. (2007) reported higher moisture and fat retention in chicken patties incorporated with egg albumen which improved the flavor, texture, and juiciness of the product. Verma et al. (2009) showed the increase in sensory scores of low salt functional chicken nuggets as a function of sunflower oil incorporation. Fig. 1 also indicated that as the level of corn bran incorporation increased, the sensory scores were decreased significantly $(p<0.01)$. Further, results of two-factor interaction showed a non-significant effect on sensory scores of nuggets except oven cooked nuggets. Talukder and Sharma (2010) reported decreased sensory quality due to wheat and oat bran incorporation in steamed and baked chicken meat patties. Similarly, Sarıçoban et al. (2009) observed wheat bran decreased the juiciness and overall sensory quality of beef patties while fat increased the juiciness. Melendres et al. (2014) reported a negative effect on sensory overall acceptability of flaxseed added beef patties. Verma et al. (2012) observed a significant $(\mathrm{p}<0.05)$ decrease in the sensory scores of chickpea hull flour incorporated chicken nuggets. Similar findings of decreased sensory attributes were also reported by Yadav et al. (2016) in chicken sausages on the addition of corn bran and Yasarlar et al. (2007) in meat balls on the addition of wheat and oat bran.

The sensory quality of emulsion based meat products were also affected by the type of cooking methods (Pathera et al., 2017). The steam cooked nuggets had shown comparatively higher sensory scores than oven and microwave cooked nuggets. The steam cooking of emulsion based meat products leads to good retention of products juiciness. The dry cooking results in lower juiciness and tenderness of products and ultimately influences the overall sensory quality of meat products. Talukder and Sharma (2010) reported higher sensory score of wheat bran incorporated steam cooked patties than oven cooked patties. Cholan et al. (2011) reported significantly $(\mathrm{p}<0.05)$ higher overall sensory scores in steam cooked patties than oven and 
(A)

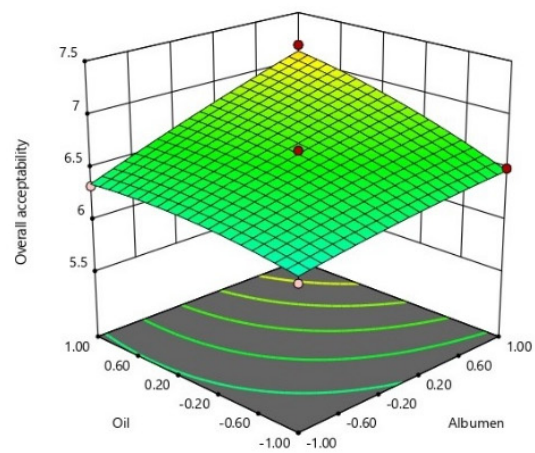

(D)

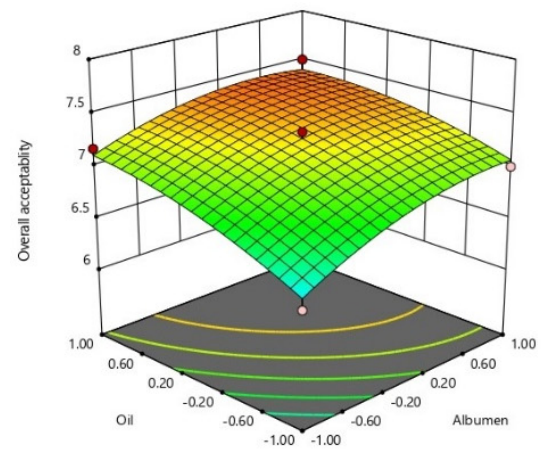

(G)

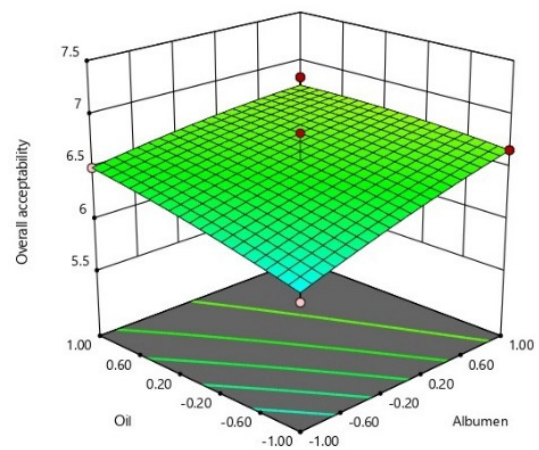

(B)

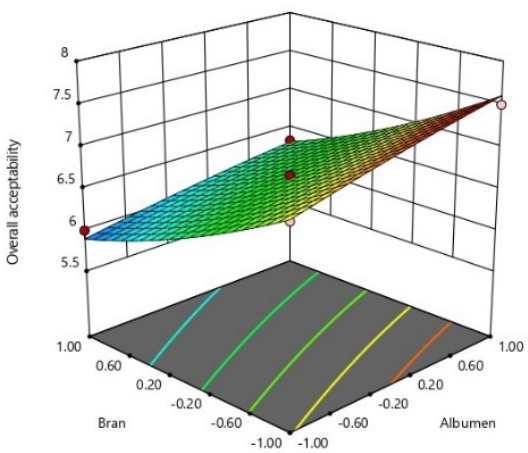

(E)

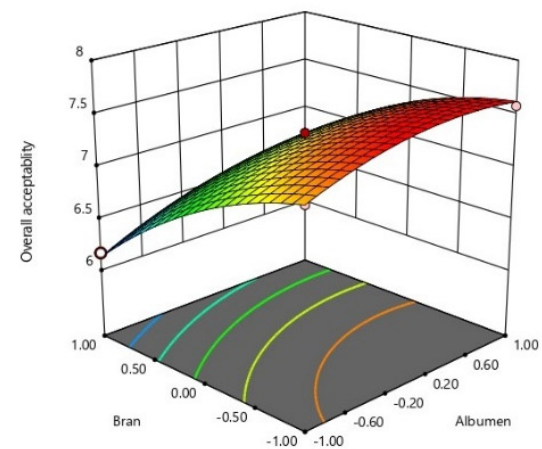

(H)

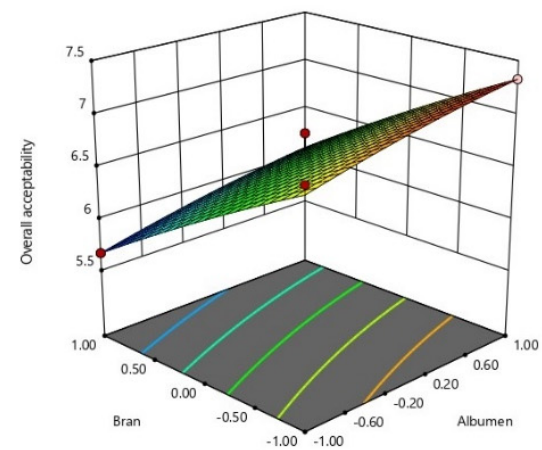

(C)

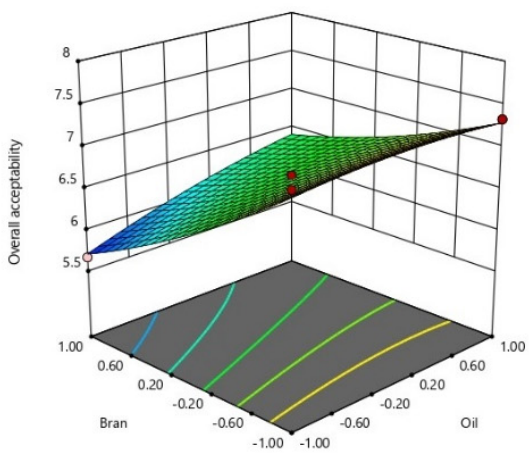

(F)

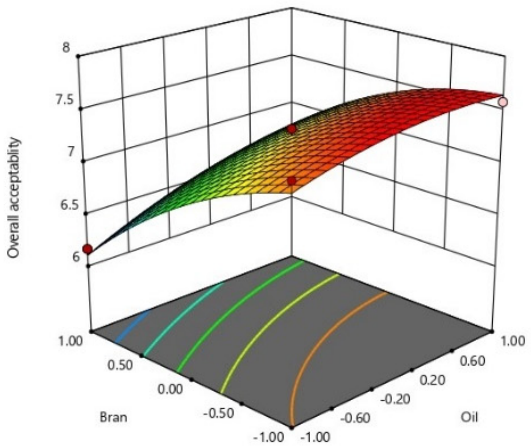

(I)

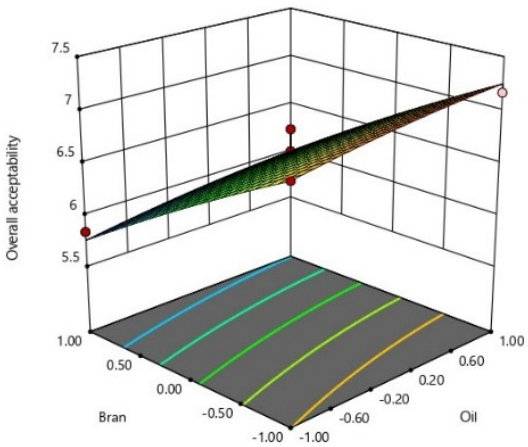

Fig. 1. Response surface 3D plot for the variation of OAA as a function of (A) albumen and oil (B) albumen and bran (C) oil and bran of oven cooked nuggets; (D) albumen and oil (E) albumen and bran (F) oil and bran of steam cooked nuggets; (G) albumen and oil (H) albumen and bran (I) oil and bran of microwave cooked nuggets. OAA, overall acceptability.

microwave cooked patties.

\section{Texture analysis}

The results of texture analysis of nuggets were presented in terms of firmness and toughness. The firmness of oven, steam, and microwave cooked nuggets varied from 9.36 to $13.65,7.72$ to 12.53 , and 7.85 to $12.22 \mathrm{~N}$ respectively (Table 1 ). The model F-values indicated that model is significant and values of $\mathrm{r}^{2}$, adjusted $\mathrm{r}^{2}$, and adequate precision indicates that the model can be used for prediction purpose (Table 3). In oven cooked nuggets, albumen and oil had no significant effect on 
Table 3. ANOVA of the regression model for responses

\begin{tabular}{|c|c|c|c|c|c|c|c|c|c|}
\hline Source & \multicolumn{3}{|c|}{ Oven cooked nuggets } & \multicolumn{3}{|c|}{ Steam cooked nuggets } & \multicolumn{3}{|c|}{ Microwave cooked nuggets } \\
\hline$\beta_{0}$ & 6.636 & 12.532 & 75.522 & 7.266 & 10.824 & 70.158 & 6.566 & 9.414 & 64.246 \\
\hline$\beta_{1}$ & $0.25^{* * *}$ & $-0.086^{\mathrm{ns}}$ & $-2.064^{\mathrm{ns}}$ & $0.208^{* * *}$ & $-0.581^{* *}$ & $-5.174^{* *}$ & $0.208^{* * *}$ & $-0.398^{* * *}$ & $-5.29^{* * *}$ \\
\hline$\beta_{2}$ & $0.186^{* * *}$ & $-0.219^{\mathrm{ns}}$ & $-5.025^{* * *}$ & $0.229^{* * *}$ & $-0.546^{* *}$ & $-3.804^{*}$ & $0.124^{* *}$ & $-0.216^{* *}$ & $-0.724^{\mathrm{ns}}$ \\
\hline$\beta_{12}$ & $0.128^{* *}$ & $-0.008^{\mathrm{ns}}$ & $0.55^{\mathrm{ns}}$ & $-0.063^{\mathrm{ns}}$ & $0.653^{* *}$ & $0.633^{\mathrm{ns}}$ & $-0.085^{\mathrm{ns}}$ & $0.083^{\mathrm{ns}}$ & $-4.418^{* *}$ \\
\hline$\beta_{13}$ & $-0.043^{\mathrm{ns}}$ & $0.05^{\mathrm{ns}}$ & $-0.073^{\mathrm{ns}}$ & $0.063^{\mathrm{ns}}$ & $-0.105^{\mathrm{ns}}$ & $-1.285^{\mathrm{ns}}$ & $0.000^{\mathrm{ns}}$ & $-0.043^{\mathrm{ns}}$ & $3.278^{* *}$ \\
\hline$\beta_{23}$ & $0.165^{* *}$ & $-0.14^{\mathrm{ns}}$ & $-4.86^{* *}$ & $0.105^{\mathrm{ns}}$ & $0.035^{\mathrm{ns}}$ & $-0.64^{\mathrm{ns}}$ & $-0.003^{\mathrm{ns}}$ & $-0.245^{* *}$ & $-2.185^{\mathrm{ns}}$ \\
\hline$\beta_{11}$ & $-0.026^{\mathrm{ns}}$ & $-0.627^{* *}$ & $-1.987^{\mathrm{ns}}$ & $-0.143^{* *}$ & $-0.581^{* *}$ & $0.160^{\mathrm{ns}}$ & $-0.034^{\mathrm{ns}}$ & $-0.447^{* * *}$ & $2.577^{*}$ \\
\hline $\mathrm{r}^{2}$ & 0.982 & 0.941 & 0.909 & 0.974 & 0.963 & 0.900 & 0.966 & 0.992 & 0.964 \\
\hline Adjusted $r^{2}$ & 0.959 & 0.866 & 0.792 & 0.940 & 0.916 & 0.771 & 0.922 & 0.981 & 0.917 \\
\hline Adeq. precision & 24.483 & 11.596 & 12.138 & 17.304 & 14.404 & 9.022 & 15.980 & 32.647 & 14.702 \\
\hline Model F-value & 42.97 & 12.499 & 7.78 & 28.77 & 20.43 & 6.982 & 21.88 & 90.87 & 20.63 \\
\hline Lack of fit F-value & 2.77 & 1.429 & 4.76 & 2.73 & 1.19 & 1.016 & 0.64 & 3.74 & 4.03 \\
\hline
\end{tabular}

${ }^{*} \mathrm{p}<0.1,{ }^{* *} \mathrm{p}<0.05,{ }^{* * *} \mathrm{p}<0.01$.

ns, non significant; OAA, overall acceptability.

firmness values but corn bran had a significant $(\mathrm{p}<0.01)$ linear effect on firmness values. In the case of steam and microwave cooked nuggets, it could be observed from Table 3 that increase in albumen or oil decreased the firmness as the coefficient of albumen $\left(x_{1}\right)$ and oil $\left(x_{2}\right)$ are negative. The positive coefficient of corn bran $\left(x_{3}\right)$ indicates that adding the corn bran increases the firmness of nuggets (Fig. 2). The interaction effects of albumen and oil ( $\left.x_{12}\right)$; oil and corn bran $\left(x_{23}\right)$ were found significant $(\mathrm{p}<0.05)$ in steam and microwave cooked nuggets respectively. Jung and Joo (2013) reported a decrease in hardness with increased level of soybean oil in pork patties. Murphy et al. (2004) observed a decrease in the force value with increased level of fat in pork sausage. Yadav et al. (2016) reported significantly $(\mathrm{p}<0.05)$ higher hardness and shear press values in corn bran added chicken sausages. Pathera et al. (2017) observed an increase in firmness of chicken nuggets with an increase in wheat bran level in the formulation. Similarly, wheat bran addition increased the hardness and firmness values in beef patties (Sariçoban et al., 2009) and meat balls (Yilmaz, 2005) respectively. Yilmaz and Dağlığlu (2003) also reported similar results of texture in oat bran added meat balls.

The toughness of oven, steam, and microwave cooked nuggets varied from 67.39 to $97.65,53.82$ to 86.67 and 54.86 to 86.14 N.sec respectively. The significant terms of the coefficient obtained by analysis of variance were presented in Table 3. The trend for toughness was almost similar to data obtained for firmness. The toughness of nuggets decreased with the increase in albumen or oil level. The increase in corn bran significantly $(p<0.01)$ increased the toughness values of all the nuggets. Fig. 3 also depicted the positive linear effect of corn bran on toughness values of nuggets. Pathera et al. (2017) noticed an increase in toughness values of chicken nuggets with an increase in wheat bran level in the formulation. Huang et al. (2005) observed an increase in hardness value of pork meat balls with the increase in rice bran level. Talukder and Sharma (2010) also reported a higher shear press value in chicken meat patties incorporated with wheat bran. 
(A)

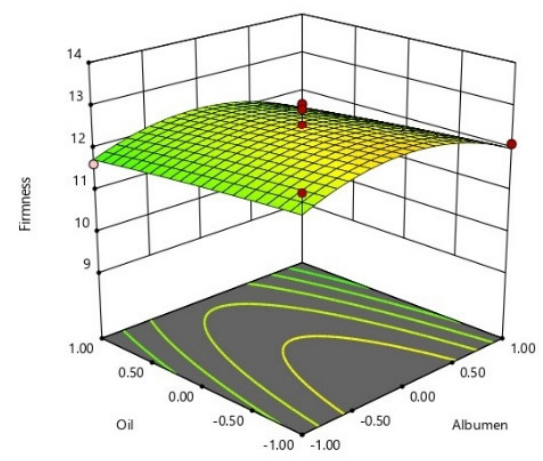

(D)

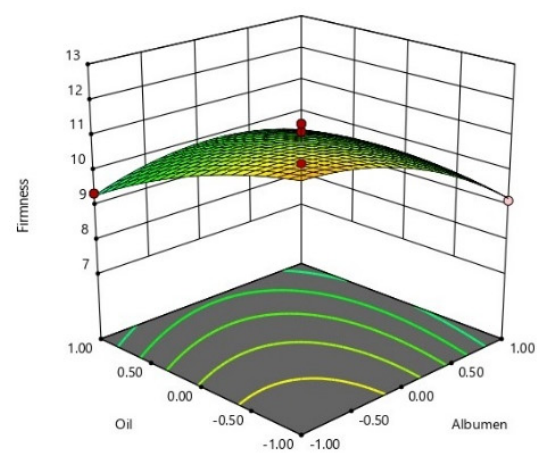

(G)

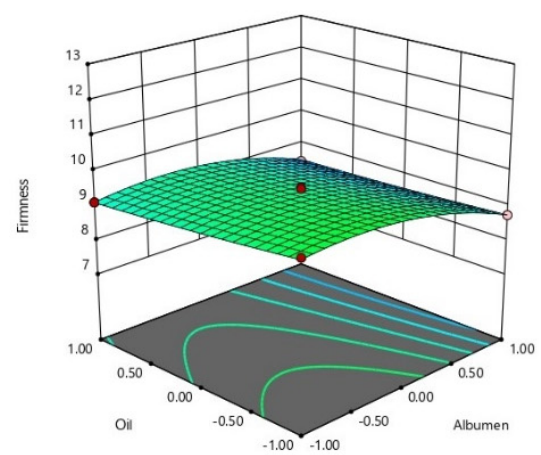

(B)

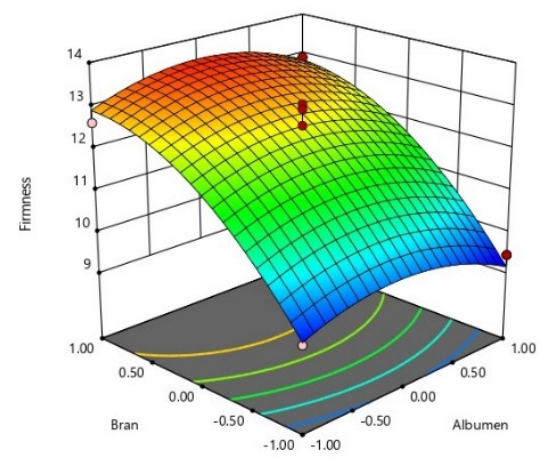

(E)

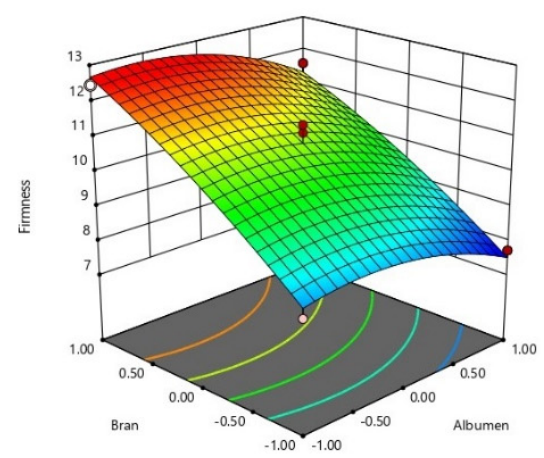

(H)

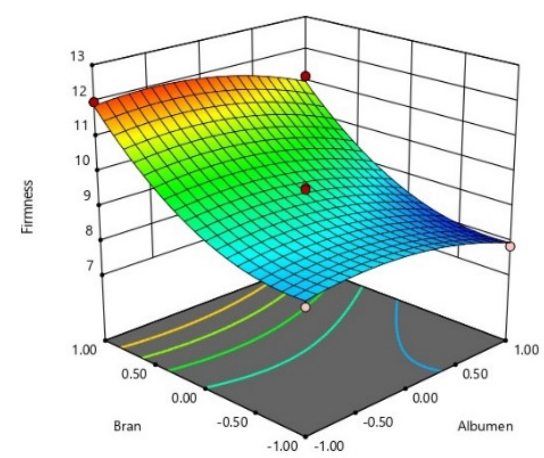

(C)

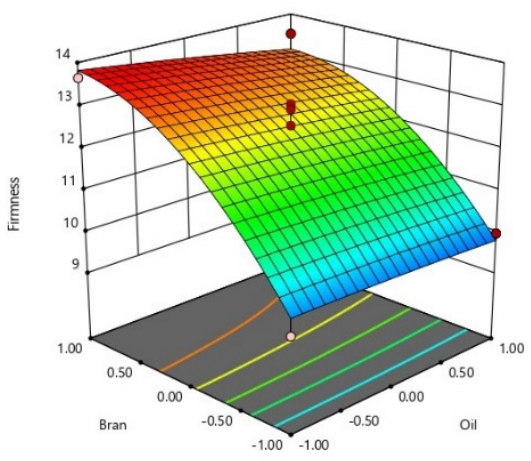

(F)

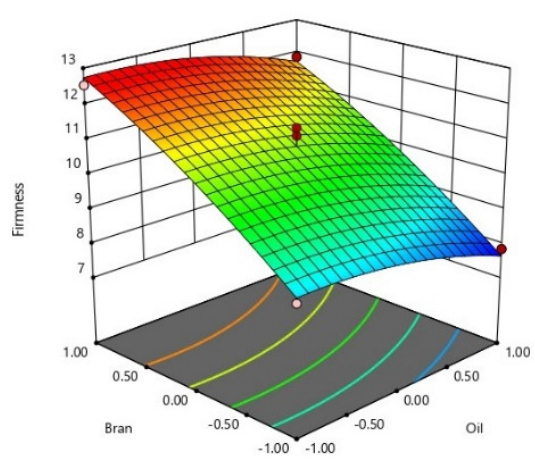

(I)

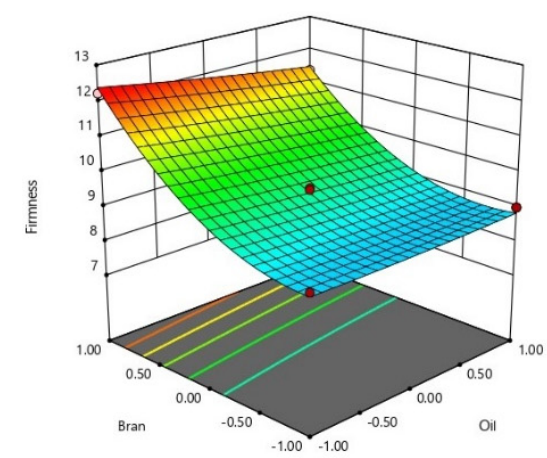

Fig. 2. Response surface 3D plot for the variation of firmness as a function of (A) albumen and oil (B) albumen and bran (C) oil and bran of oven cooked nuggets; (D) albumen and oil (E) albumen and bran (F) oil and bran of steam cooked nuggets; (G) albumen and oil (H) albumen and bran (I) oil and bran of microwave cooked nuggets.

The cooking methods affected the textural quality of oven, steam, and microwave cooked nuggets. The firmness and toughness values of oven cooked nuggets were found higher than steam and microwave cooked nuggets. The effect of dry heat might be the reason for higher values of firmness and toughness of oven cooked nuggets. Another reason for the harder texture of oven cooked nuggets might be the more moisture loss in the oven cooking in comparison to other cooking methods. The firmness and toughness values of steam and microwave cooked nuggets were found almost in similar range. Talukder and Sharma (2010) noticed significantly $(\mathrm{p}<0.05)$ lower shear press values of steam cooked patties than oven cooked patties. Pathera et al. (2017) also observed the similar effect of cooking methods on textural quality of dietary fiber enriched chicken nuggets. 
(A)

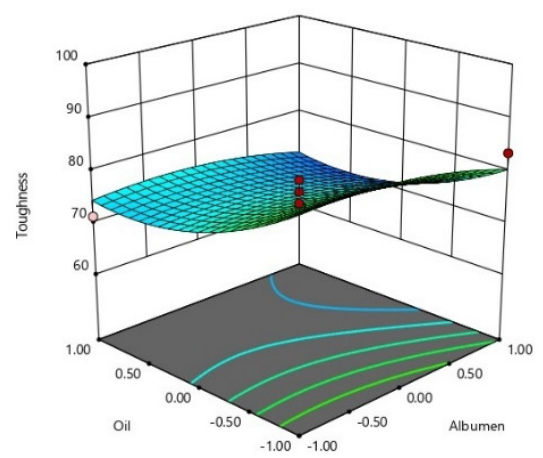

(D)

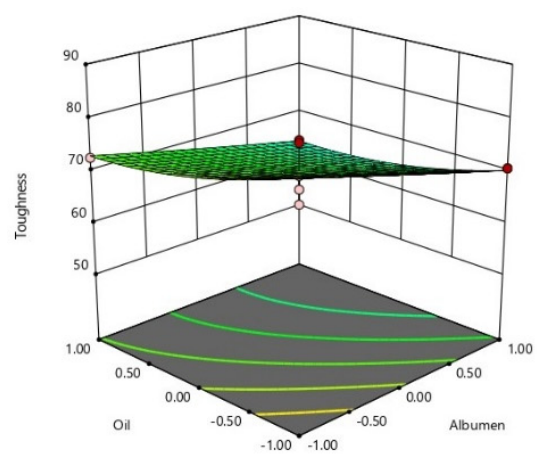

(G)

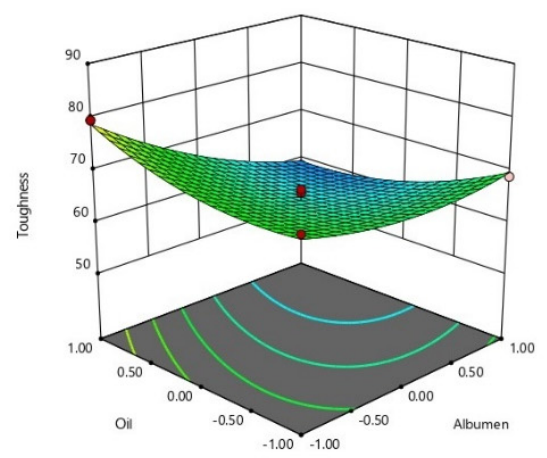

(B)

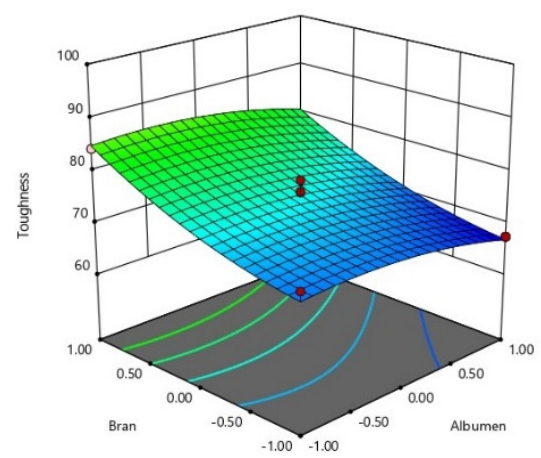

(E)

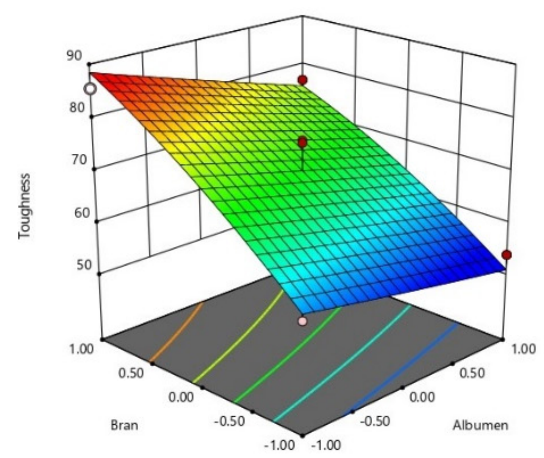

(H)

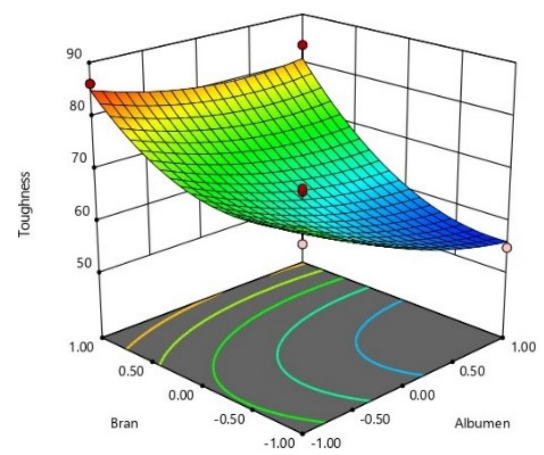

(C)

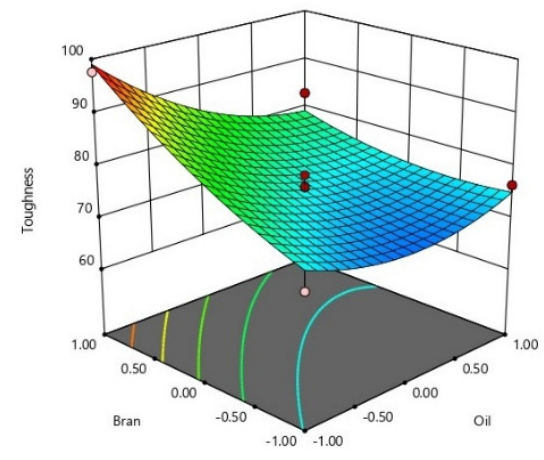

(F)

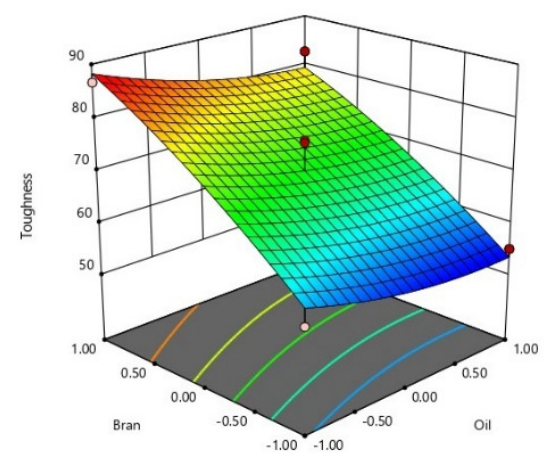

(I)

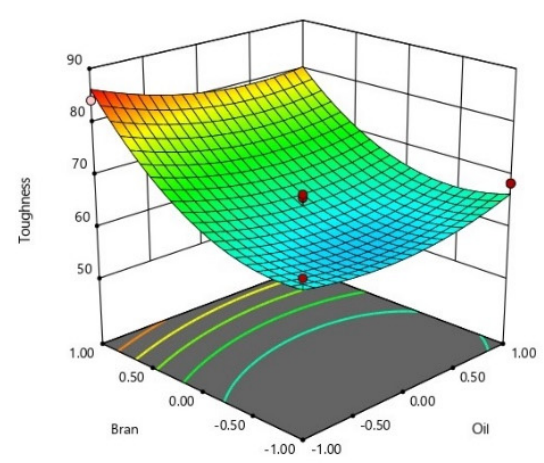

Fig. 3. Response surface 3D plot for the variation of toughness as a function of (A) albumen and oil (B) albumen and bran (C) oil and bran of oven cooked nuggets; (D) albumen and oil (E) albumen and bran (F) oil and bran of steam cooked nuggets; (G) albumen and oil (H) albumen and bran (I) oil and bran of microwave cooked nuggets.

\section{Product optimization}

The numerical multi-response optimization technique with desirability function in Design Expert software was used to estimate the optimum level of egg albumen, vegetable oil, and corn bran. Three optimum formulations for nuggets having desirability of 1 were determined for each cooking method. These optimum formulations were used to manufacture nuggets by respective cooking methods. The predicted values of response were validated against actual values of responses at the optimized condition of experiments. The formulations for nuggets having least deviation (less than 5\%) in actual values of response against predicted values were presented in Table 4 and found best among respective 3 optimum formulations. 
Table 4. Predicted and actual values of responses at the optimized condition of experiments

\begin{tabular}{|c|c|c|c|c|c|c|}
\hline & \multicolumn{3}{|c|}{ Level of ingredients (g) } & \multicolumn{3}{|c|}{$\%$ Deviation } \\
\hline & Egg albumen & Vegetable oil & Corn bran & OAA & Firmness & Toughness \\
\hline Oven cooked nuggets & 8.74 & 11.69 & 9.89 & 2.30 & 2.09 & 3.10 \\
\hline Steam cooked nuggets & 11.54 & 8.26 & 11.74 & 1.35 & 3.42 & 2.49 \\
\hline Microwave cooked nuggets & 10.67 & 8.63 & 8.98 & 0.24 & 4.74 & 4.43 \\
\hline
\end{tabular}

OAA, overall acceptability.

\section{Conclusion}

The sensory and texture are important quality parameters for development of meat products. Increasing level of egg albumen or vegetable oil increased the sensory scores and decreased the firmness and toughness values of nuggets. The increase in corn bran level decreased the sensory scores and increased the firmness and toughness values of nuggets. Therefore, optimum levels of egg albumen, vegetable oil, and corn bran were determined based on the sensory and textural quality of nuggets. The results obtained would be useful for the meat products manufacturer which tends to enrich the dietary fiber in meat products having good sensory and textural quality.

\section{Acknowledgements}

The authors would like to thank Department of Livestock Products Technology, Lala Lajpat Rai University of Veterinary and Animal Sciences (Haryana, India) for technical assistance during this study.

\section{References}

Box GEP, Behnken DW. 1960. Some new three level designs for the study of quantitative variables. Technometrics 2:455-475. Cholan P, Rao VK, Karthikeyan B, Moorthy PRS, Cytyarasan S. 2011. Effect of different cooking methods on physicochemical, organoleptic and microbiological quality of chicken patties. Ind J Poult Sci 46:206-210.

Dhingra D, Michael M, Rajput H, Patil RT. 2012. Dietary fibre in foods: A review. J Food Sci Technol 49:255-266.

Huang SC, Shiau CY, Liu TE, Chu CL, Hwang DF. 2005. Effects of rice bran on sensory and physico-chemical properties of emulsified pork meatballs. Meat Sci 70:613-619.

Jung E, Joo N. 2013. Roselle (Hibiscus sabdariffa L.) and soybean oil effects on quality characteristics of pork patties studied by response surface methodology. Meat Sci 94:391-401.

Kalaikannan A, Anjaneyulu ASR, Santhi D. 2007. Effect of egg proteins on the quality and refrigerated storage life of chicken patties made with broiler-spent hen meat and by-products. Int J Food Sci Technol 42:579-586.

Kaushik R, Kumar N, Sihag MK, Ray A. 2015. Isolation, characterization of wheat gluten and its regeneration properties. J Food Sci Technol 52:5930-5937.

Kumar N, Khatkar BS, Kaushik R. 2013. Effect of reducing agents on wheat gluten and quality characteristics of flour and cookies. Ann Univ Dunarea de Jos Galati - Food Technol 37:68-81.

Melendres MV, Camou JP, Torrentera Olivera NG, Álvarez Almora E, González Mendoza D, Avendaño Reyes L, González Ríos H. 2014. Response surface methodology for predicting quality characteristics of beef patties added with flaxseed and tomato paste. Meat Sci 97:54-61. 
Murphy SC, Gilroy D, Kerry JF, Buckley DJ, Kerry JP. 2004. Evaluation of surimi, fat and water content in a low/no added pork sausage formulation using response surface methodology. Meat Sci 66:689-701.

Pathera AK, Riar CS, Yadav S, Sharma DP, Yadav YS, Kumar M. 2017. Optimization of dietary fiber enriched chicken nuggets for different cooking methods. J Food Meas Charact 11:1386-1397.

Pathera AK, Riar CS, Yadav S, Singh PK. 2016. Effect of cooking methods on lipid oxidation, microbiological and sensory quality of chicken nuggets under refrigerated storage. Cogent Food Agric 2:1232472.

Prasad K, Singh Y. 2014. Rice based vegetable supplemented functional instant soup mix: Development and optimization. Scholar's Press, Germany. p 84.

Ramezanzadeh FM, Rao RM, Prinyawiwatkul W, Marshall WE, Windhauser M. 2000. Effects of microwave heat, packaging, and storage temperature on fatty acid and proximate compositions in rice bran. J Agric Food Chem 48:464-467.

Sarıçoban C, Yılmaz MT, Karakaya M. 2009. Response surface methodology study on the optimisation of effects of fat, wheat bran and salt on chemical, textural and sensory properties of patties. Meat Sci 83:610-619.

Talukder S, Sharma DP. 2010. Development of dietary fiber rich chicken meat patties using wheat and oat bran. J Food Sci Technol 47:224-229.

Verma AK, Benerjee R, Sharma BD. 2012. Quality of low fat chicken nuggets: Effect of sodium chloride replacement and added chickpea (Cicer arietinum L.) hull flour. Asian-Australas J Anim Sci 25:291-298.

Verma AK, Sharma BD, Banerjee R. 2009. Efficacy of sunflower oil levels on the physico-chemical and sensory properties of low salt functional chicken nuggets. J Vet Public Health 7:53-57.

WHO/FAO. 2003. Diet, nutrition and prevention of chronic diseases: Report of a joint WHO/FAO expert consultation. WHO Technical report series 916.

Yadav S, Malik A, Pathera A, Islam RU, Sharma D. 2016. Development of dietary fiber enriched chicken sausages by incorporating corn bran, dried apple pomace and dried tomato pomace. Nutr Food Sci 46:16-29.

Yasarlar EE, Daglioglu O, Yilmaz I. 2007. Effect of cereal bran addition on chemical composition, cooking characteristics and sensory properties of Turkish meatballs. Asian J Chem 19:2353-2361.

Y1lmaz I. 2005. Physicochemical and sensory characteristics of low fat meatballs with added wheat bran. J Food Eng 69:369373.

Yilmaz I, Dağlığlu O. 2003. The effect of replacing fat with oat bran on fatty acid composition and physicochemical properties of meatballs. Meat Sci 65:819-823. 